\title{
A sustentabilidade e o desenvolvimento sustentável na educação em engenharia
}

\author{
Sustainability and sustainable development in engineering education \\ Solange Maria Loureiro ${ }^{1 *}$, Vera Lúcia Duarte do Valle Pereira² e Waldemar Pacheco Junior ${ }^{3}$ \\ ${ }^{1}$ Doutora em Engenharia de Produção, Universidade Federal de Santa Catarina (UFSC), Brasil \\ ${ }^{2}$ Doutora em Engenharia Mecânica, UFSC, Brasil. Professora Voluntária da UFSC, Brasil. \\ ${ }^{3}$ Professor e consultor em Engenharia de Segurança do Trabalho.
}

\begin{abstract}
Resumo
Um dos desafios deste século se relaciona à perspectiva de que as sociedades se tornem social, ambiental e economicamente sustentáveis, de forma a satisfazerem as necessidades das presentes gerações sem diminuir as chances de as futuras gerações satisfazerem as delas. É por meio da educação superior que novos profissionais passam a atuar, logo, influenciam a maneira como as gerações atuais e as futuras lidam com as questões sociais, ambientais e econômicas, ou seja, com a sustentabilidade e com o Desenvolvimento Sustentável (DS). Assim, cabe à educação superior proporcionar às pessoas competências que permitam a elas enfrentarem os desafios técnicos e socioambientais por meio de soluções que minimizem os impactos ambientais e as desigualdades sociais. Como os(as) engenheiros(as) têm uma relação direta com a produção de conhecimento e tecnologias que impactam diretamente a sociedade e o ambiente é imprescindível que a formação em engenharia permita que eles(as) projetem tecnologias e atividades econômicas que sustentem em vez de degradarem o ambiente natural e melhorem a saúde e o bem-estar humano. Nesse contexto, é objetivo desse trabalho refletir acerca da visão de sustentabilidade necessária à educação em engenharia para que a mesma possa contribuir para tornar as sociedades sustentáveis.
\end{abstract}

Palavras-chave: Sustentabilidade. Desenvolvimento sustentável. Educação em engenharia.

\begin{abstract}
One of the challenges of this century is related to the perspective that the societies become socially, environmentally and economically sustainable in order to satisfy the needs of present generations without reducing the chances of the future generations to achieve theirs. It is through higher education that new professionals start acting, thus, influence how current and future generations deal with the social, environmental and economic issues, i.e., with the sustainability and the Sustainable Development (SD). So, it is responsibility of higher education to provide to the people competencies to enable them to deal with the technical and environmental challenges through solutions that minimize environmental impacts and social inequalities. As the engineers have direct relationship to the production of knowledge and technologies that directly impact society and the environment is essential that the engineering background allows them to design technologies and economic activities to sustain rather than degrade the natural environment and improve health and human well-being. In this context, this paper aims to reflect about the vision of sustainability/DS required for engineering education so that it may contribute to make sustainable societies.
\end{abstract}

Keywords: Sustainability. Sustainable development. Engineering education. 


\section{Introdução}

Um dos desafios deste século se relaciona à perspectiva de que as sociedades se tornem social, ambiental e economicamente sustentáveis, de forma a satisfazerem as necessidades das presentes gerações sem diminuir as chances de as futuras gerações satisfazerem as delas. Para tanto, é necessário rever a visão de mundo ${ }^{1}$ na qual se fundamenta a racionalidade ocidental, priorizando o pensamento integrado que percebe as interdependências entre os fenômenos sociais, ambientais e econômicos. Entende-se que o estabelecimento de uma educação comprometida com mudanças de valores e de comportamentos, individuais e coletivos, poderá auxiliar na construção dessas sociedades.

Nesse contexto, a educação de nível superior tem um papel prioritário à medida que os futuros profissionais são os que trabalharão com os recursos sociais, ambientais e econômicos e, portanto, precisam perceber sua função na busca por transformações sociais e melhoria de bem-estar para as pessoas das gerações atuais e das próximas. Em relação à engenharia, a atuação dos(as) engenheiros(as) podem causar impactos, muitas vezes, prejudiciais à qualidade de vida das pessoas, de outros seres vivos e dos ecossistemas, logo, é imprescindível que eles(as) possam refletir sobre sua atuação e sejam formados para buscarem soluções sustentáveis para os problemas profissionais que encontrarão, colaborando, assim, com a sociedade na qual atuam. Mas, qual a visão de sustentabilidade e de Desenvolvimento Sustentável (DS) necessária à educação em engenharia?

Assim, este artigo visa refletir, fundamentado em literatura, acerca da visão de sustentabilidade/DS necessária à educação em engenharia para que a mesma possa contribuir para tornar as sociedades sustentáveis².

\section{Educação e sustentabilidade/DS}

A forma de educação que, em nível mundial, está sendo preconizada para enfrentar o desafio de construção de sociedades sustentáveis é a Educação para o Desenvolvimento Sustentável (EDS) ou a Educação para a Sustentabilidade (EpS). É por meio da EDS/EpS que a sustentabilidade/DS está sendo incorporada aos currículos nos vários níveis de ensino em diversos países do mundo (JICKLING; WALS, 2008; WRIGHT, 2009; CORTESE; HATTAN, 2010; MANTEAW, 2010; DOBSON; QUILLEY; YOUNG, 2010). Essa forma de educação passou a ser preconizada internacionalmente pela Organização das Nações Unidas (ONU) a partir de 2002 e tem como meta beneficiar as pessoas com uma educação em que seus valores e comportamentos possam gerar e gerir sociedades sustentáveis.

Dessa forma, para superar o paradigma atual, a EDS/EpS deve pautar-se pela dimensão ética, visando que os valores e as práticas das sociedades atuais sejam questionados e, também, que se identifiquem e se construam novos consensos estabelecidos pela participação social, ética da responsabilidade e defesa da vida (JACOBI, 2005; BARBIERI; SILVA, 2011). A superação do paradigma atual, que se sustenta nos princípios da determinação, da separação, da redução e da lógica clássica, requer, ainda, que a EDS/EpS seja construída pelos princípios da complexidade e da interdisciplinaridade. A complexidade percebe o mundo como um evento aberto ao novo e ao inesperado, no qual os diversos elementos se interconectam, gerando características singulares tanto quanto universais (JACOBI, 2005; JACOBI, RAUFFLET; ARRUDA, 2011). A complexidade dos problemas atuais relaciona-os a várias áreas do conhecimento e a várias dimensões, assim só conseguem ser apreendidos se vistos de forma interdisciplinar, em que ocorre a integração das várias áreas e dimensões, e não apenas a reunião das mesmas. Para que a EDS/EpS possa responder aos problemas complexos precisa ultrapassar o que Lima (2003) denomina de "sustentabilidade de mercado", ou seja, deve ser capaz de rever velhos modelos e buscar novas concepções individuais e coletivas, sociais e ambientais.

\subsection{O contexto da EDS/EpS para a Educação Superior}


O desafio da educação superior para adotar a EDS/EpS está colocado em um cenário de mercado globalizado e competitivo, no qual o capitalismo se reinventa por meio da globalização e da competitividade, exigindo mais nível educacional dos trabalhadores e competências ${ }^{3}$ que devem ir além das puramente técnicas, sem, no entanto, acenar com mais empregos e/ou salários (SANTOS; ANDRIOLI, 2005; CORDEIRO et al., 2008). A educação superior é muitas vezes confundida e realizada como treinamento para o que o mercado determina. Entretanto, o ensino superior é, muitas vezes, a porta de entrada para a vida adulta e profissional. É nas Instituições de Ensino Superior (IES) que a identidade profissional básica é desenvolvida.

Assim, cabe à educação superior proporcionar às pessoas conhecimentos, habilidades e atitudes, ou seja, competências que permitam a elas enfrentarem os desafios técnicos e socioambientais por meio de soluções que minimizem os impactos ambientais e as desigualdades sociais. É por meio da educação superior que novos profissionais passam a atuar, logo, influenciam a maneira como as gerações atuais e as futuras lidam com as questões sociais, ambientais e econômicas, ou seja, com o DS. Acredita-se ser possível que a educação superior possa estabelecer formações que possibilitem uma nova forma de os seres humanos se relacionarem entre si e com a natureza, por meio de uma ética que priorize a dimensão coletiva (RATTNER, 2002; JACOBI, 2005; AZNAR MINGUET; ULL SOLÍS, 2009; TOZONI-REIS, 2011; MINTZ e TAL, 2013).

Em nível internacional, passou-se a construir a Educação Superior para a Sustentabilidade por meio de vários instrumentos e declarações assinadas por diversas universidades ao redor do mundo. $\mathrm{Na}$ Comunidade Europeia criou-se o Espaço Europeu de Educação Superior (EEES), que visa propiciar uma educação comprometida com a EDS/EpS, nas IES naquela comunidade, conforme preconizada pela Unesco (WRIGHT, 2002; EDWARDS; ÁLVAREZ-SÁNCHEZ; SÁNCHEZ-RUIZ, 2007; MARTÍNEZ AGUT et al., 2007; ROHWEDER; VIRTANEN, 2009; ULL SOLÍS et al., 2010). Ainda, em nível internacional, surgiram outras iniciativas com vistas a implementar o Ensino Superior para o Desenvolvimento Sustentável, como, por exemplo, a Parceria de Sustentabilidade Global para o Ensino Superior (GHESP), a Associação Internacional de Universidades (IAU), e a Organização Internacional de Universidades para o Desenvolvimento Sustentável e o Meio Ambiente (OIUDSMA), dentre outras. Essas iniciativas inspiraram vários congressos, encontros e conferências que evidenciam o interesse da educação superior em discutir os rumos da educação voltada ao DS (SEGALÀS, 2008; LAYRARGUES, 2012).

Dentre as iniciativas que evidenciam o interesse da inclusão da sustentabilidade no ensino superior está a Declaração de Talloires. Essa declaração foi escrita em 1990, na França, sendo a primeira assumida por administradores de universidades que firmaram um compromisso voluntário dessas instituições com a sustentabilidade em seus vários níveis de atuação, ou seja, na administração do campus, no ensino, na pesquisa e na extensão (WRIGHT, 2002; BARBIERI; SILVA, 2011; LAYRARGUES, 2012). Ela constitui-se, basicamente, de dez macroações por meio das quais as IES possam participar mais ativamente na busca de novas formas de pensar o desenvolvimento (BARBIERI; SILVA, 2011). Assinar essa Declaração é comprometer-se com a sustentabilidade no ensino superior, sendo que em 2010, 429 universidades em todo o mundo já tinham efetivado esse compromisso (ADLONG, 2013). Por sua vez, a OIUDSMA congrega 14 países e um total de 60 universidades signatárias (LAYRARGUES, 2012). Essas iniciativas, internacionais ou regionais, são todas voluntárias e expressam, pelo menos em nível de discurso, a intenção de atuar proativamente visando o DS.

No contexto brasileiro, algumas universidades assinaram acordos e declarações internacionais com vistas à inclusão do tema sustentabilidade em suas atividades, sendo que 52 delas assinaram a Declaração Talloires, praticamente todas são universidades federais, e 8 se tornaram signatárias da OIUDSMA (LAYRARGUES, 2012). Contudo, Henriques et al. (2007) evidenciaram que pesquisas realizadas em IES brasileiras apontam a falta de políticas públicas e institucionais como um obstáculo para a implementação da sustentabilidade/DS nessas instituições.

\subsection{O contexto da EDS/EpS para o ensino de engenharia}

REGET - V. 20, n. 1, jan.- abr. 2016, p.306-324 
No contexto da educação superior, os(as) engenheiros(as) têm uma relação direta com a produção de conhecimento e tecnologias que impactam diretamente a sociedade e o meio ambiente. Dessa forma, é imprescindível se formarem engenheiros(as) que projetem tecnologias e atividades econômicas que sustentem em vez de degradarem o ambiente natural e melhorem a saúde e o bemestar humano (SEGALÀS, 2008; HANNING et al., 2012). Assim, é necessário um novo tipo de engenheiro(a) que seja consciente de seu papel social além de seu compromisso técnico e que saiba lidar com os aspectos sociais das tecnologias (BAZZO; PEREIRA; LINSINGEN, 2000; CARVALHO; PORTO; BELHOT, 2001; LINSINGEN, 2002; LINSINGEN; PEREIRA; BAZZO, 2003; SEGALÀS, 2008; TONINI; DUTRA, 2009; MULDER; SEGALÀS; FERRER-BALAS, 2010; QUELHAS; FRANÇA; TRAVINCAS, 2011; HANNING et al., 2012). Tem sido por meio de competências para a sustentabilidade/DS 4 que se tem procurado mudar o ensino de engenharia em outros países. Várias propostas de competências para a sustentabilidade/DS têm sido apresentadas por partes interessadas, pesquisadores, agências de acreditação ${ }^{5}$, governos, associações, dentre outras. A maioria das abordagens concentra-se em conteúdo curricular e plano de estudos, com pouca atenção à concepção curricular - processo muito mais amplo - que possa facilitar a aquisição das competências (BARTH et al., 2007; SEGALÀS, 2008; MULDER; SEGALÀS; FERRER-BALAS, 2010; RIECKMANN, 2012).

No Brasil, alguns pesquisadores, dentre os quais, Linsingen (s/d), Bazzo, Pereira e Linsingen (2000), Linsingen (2002), Linsingen, Pereira e Bazzo (2003), Brito (2011), Carletto (2011), Dwek, Coutinho e Matheus (2011), há algum tempo, apontam a necessidade de se redirecionar a formação tecnológica da área de engenharia na perspectiva de que os futuros engenheiros(as) percebam as múltiplas implicações da engenharia com as dimensões sociais, ecológicas, culturais e econômicas da tecnologia. Esses autores dizem que o ensino de engenharia no Brasil ocorre com forte ênfase tecnicista, ou seja, com boa preparação do aluno para lidar com os aspectos técnicos relativos à sua profissão - o que se entende ser imprescindível - no entanto, com pouca preparação dos mesmos para os aspectos mais amplos relacionados à sua atuação como seres humanos e como cidadãos responsáveis. Dessa forma, os autores sugerem que vários aspectos envolvendo questões pedagógicas, filosóficas, epistemológicas, dentre outras, devam ser consideradas nessa formação a luz das abordagens CTS. Por sua vez, Linsingen (2002), em sua tese de doutorado, realiza uma análise crítica da formação em engenharia, orientado pelas abordagens CTS, sugerindo que para formar engenheiros(as) mais comprometidos socialmente, há a necessidade de se associar à essa formação a dimensão sócio-eco-sistêmica da tecnologia, a qual percebe de forma sistêmica o entrelaçamento socioambiental dos diversos problemas associados ao desenvolvimento e uso das tecnologias por meio da engenharia.

Entretanto, a proposta de incorporação da EDS/EpS em cursos de engenharia no Brasil e a defesa em se trabalhar com a sustentabilidade têm-se efetivado por meio de algumas iniciativas individualizadas, como, por exemplo, nas propostas de: Carletto (2011), em que a autora propõe alternativas e princípios educativos relacionados à sustentabilidade para estimular a Avaliação de Impacto Tecnológico (AIT) na educação em engenharia; Quelhas, França e Travincas (2011) que propõem o ensino para a engenharia com foco na sustentabilidade e apresentam um estudo de caso efetuado na escola de engenharia da Universidade Federal Fluminense (UFF), envolvendo a disciplina de Gestão Estratégica Industrial; Adeodato et al. (2004) que relatam uma experiência vivenciada na Universidade Federal de São Carlos (UFSCar), na graduação de Engenharia Civil, que por meio do Programa de Atividade Curricular de Integração Ensino, Pesquisa e Extensão (ACIEPE), utilizam a disciplina Sustentabilidade Urbana e Regional e projetos de extensão para estimular os alunos a assimilarem novas práticas e processos de interação com o ambiente e a sociedade enquanto profissionais e pesquisadores.

A visão de sustentabilidade/DS que se apresenta nos cursos de engenharia atualmente possui, segundo Moraes (2011), um forte atrelamento à dimensão ambiental. O autor identificou esse aspecto em pesquisa efetuada com professores e alunos de cursos de engenharia da Universidade Tecnológica Federal do Paraná (UTFPR), Campus Curitiba. Nessa pesquisa Moraes (2011) identifica que, tanto os docentes quanto os discentes, associam facilmente à Educação Ambiental, questões que envolvem degradação ambiental, poluição, reciclagem, energia renovável, dentre outros assuntos, cujo foco é o

REGET - V. 20, n. 1, jan.- abr. 2016, p.306-324 
ambiente, porém, são raros os que realizam conexões com outras dimensões referidas à sustentabilidade. Moraes (2011), ainda, conclui que o engenheiro na UTFPR tem sido formado principalmente para as questões técnicas, faltando-lhe uma visão global sobre como suas atividades interagem com o contexto social, ambiental, cultural, econômico. Um aspecto, segundo Nascimento (2012), que pode contribuir para reforçar a dimensão ambiental é a visão de mundo, equivocada, de que a sustentabilidade/DS é uma forma de se salvar o planeta, pois o foco da proposta de DS é o ser humano e sua permanência no planeta.

Entende-se ser o papel das engenharias acerca da sustentabilidade/DS o de atendimento às demandas da sociedade promovendo qualidade de vida, mas considerando parâmetros éticos e de responsabilidade socioambiental, conforme o artigo $3^{\text {o }}$ da Resolução 11 do Conselho Nacional de Educação/Câmara de Educação Superior (CNE/CES), de 11 de março de 2002, que estabelece as Diretrizes Curriculares Nacionais dos Cursos de Engenharia, o qual propõe que o novo engenheiro deva ter perfil de

formação generalista, humanista, crítica e reflexiva, capacitado a absorver e desenvolver novas tecnologias, estimulando a sua atuação crítica e criativa na identificação e resolução de problemas, considerando seus aspectos políticos, econômicos, sociais, ambientais e culturais, com visão ética e humanística, em atendimento às demandas da sociedade (BRASIL, 2002, p. 1).

Dessa forma, refletir sobre as visões de sustentabilidade/DS na educação em engenharia é imprescindível para que essa formação possa contribuir com o desafio de construção de sociedades sustentáveis.

\section{Visões de Sustentabilidade e Desenvolvimento Sustentável (DS)}

Para Faber, Jorna e Engelen (2005), os sistemas biológicos são inerentemente sustentáveis, pois quando o equilíbrio entre os sistemas biológicos é perturbado esses se comportam de maneira a restaurá-lo. Já os sistemas artificiais - que os autores chamam de artefatos, definindo-os como qualquer construção humana - quando afetados por um desequilíbrio, em sua maioria, não conseguem restabelecer suas capacidades, o que pode levá-los a situações insustentáveis ou até ao colapso. Os sistemas artificiais podem ser muito complexos e gerarem comportamentos imprevisíveis. Para esses autores, os sistemas artificiais relacionam-se com os naturais por meio da limitação imposta pelos últimos a possibilidades de existência dos primeiros. A limitação imposta pelos sistemas naturais ocorre por meio do fornecimento finito de recursos ou pelos mesmos serem sumidores dos resíduos gerados pelos sistemas artificiais. Assim, a sustentabilidade não deve ser negligenciada para os sistemas artificiais porque não se podem identificar previamente todos os impactos que esses sistemas são capazes de produzir.

Nesse contexto, Faber, Jorna e Engelen (2005) sugerem que três aspectos devam ser considerados para se avaliar a sustentabilidade de sistemas artificiais, quais sejam: o tipo de artefato (entidade ou construto); a orientação a objetivos (absoluta ou relativa); e, a interação comportamental (estática ou dinâmica). Esses aspectos definem para os autores formas mais ou menos adequadas de se trabalhar com o conceito de sustentabilidade. Assim, quando se vê o artefato como entidade percebe-se o mesmo de forma isolada, por sua vez, enquanto construto, o mesmo deve ser analisado em um contexto mais amplo de utilização. Usando-se como exemplo o carro, visto na perspectiva de entidade, percebe-se que ele pode adquirir a propriedade de sustentabilidade, sem que o mesmo esteja realmente em conformidade com essa ideia, se, por exemplo, o combustível gasolina for trocado por células a combustível. No entanto, se o artefato carro for visualizado dentro de um sistema mais amplo (construto), no qual todas as pessoas maiores de 18 anos possam dirigir, a complexidade do sistema aumenta muito, e o carro, nesse contexto, dificilmente seria considerado sustentável mesmo utilizando um combustível renovável. Dessa forma, visualizar o carro como construto implica 
considerar o sistema de interações que ocorrem entre o artefato e o meio (ambiental, social e econômico).

Com relação à orientação a objetivos (absoluta ou relativa), proposta por Faber, Jorna e Engelen (2005), tem-se uma perspectiva absoluta quando se consideram pontos discretos (extremos) em que o artefato é sustentável/não sustentável. Nessa abordagem existe uma forma implícita de sustentabilidade ideal. Na orientação relativa, por sua vez, identifica-se o estado atual de coisas que envolvem o artefato e tenta-se resolver gradativamente as questões de sustentabilidade. É uma abordagem que visa trabalhar com pequenos passos, mas continuamente em prol da sustentabilidade.

Para Faber, Jorna e Engelen (2005) na interação comportamental deve-se observar se a dinâmica entre o artefato e o meio é contabilizada. Considerando-se que tanto o artefato como o meio podem sofrer alterações, devidas a forças exógenas ou endógenas, a atribuição da interação comportamental para um artefato pode ser classificada como estática ou dinâmica. Na perspectiva estática, considerase que o artefato pode sofrer alterações, mas o meio permanece inalterado. Assim, nesta visão, de forma ilusória, obedecendo-se às limitações do meio, sempre será possível assegurar a sustentabilidade de sistemas artificiais. Nessa perspectiva, o desconhecimento sobre os impactos das tecnologias não é considerado, sendo um ponto de vista perigoso para a sustentabilidade. Por outro lado, a perspectiva dinâmica considera que tanto o artefato quanto o meio podem mudar devido à atuação de forças endógenas e/ou exógenas, influenciando a sustentabilidade. Assim, para alcançar a sustentabilidade o artefato precisa encontrar, continuamente, faixas de mudanças e se adaptar para manter o equilíbrio.

Com base em sua perspectiva de análise para a sustentabilidade de sistemas artificiais, apresentados anteriormente, Faber, Jorna e Engelen (2005) consideram que houve evolução conceitual sobre a sustentabilidade, entre o período de 1960 e 2000, observado à luz dos aspectos por eles elaborados. Assim, os autores consideram que o DS pode ser considerado um vetor de objetivos sociais desejáveis e que a sustentabilidade descreve um estado de transição que precisa ser mantido para sempre, visando à manutenção da vida. Para eles, o fato de o conceito de sustentabilidade evoluir de uma perspectiva absoluta para relativa e de estática para dinâmica permite que se aja sobre o estado presente, tentando minimizar os problemas para, se possível, garantir às gerações futuras a possibilidade de acesso aos recursos naturais do presente e melhor qualidade de vida.

Para Osório, Lobato e Castilho (2005), a sustentabilidade é apresentada como a capacidade de manutenção de um estado, enquanto o DS ocorre como um processo para tentar manter um estado de equilíbrio dinâmico de longo prazo, no qual a sustentabilidade é a ideia central.

Embora haja uma diversidade de conceitos sobre sustentabilidade e DS Waas et al. (2011) concluem que há um consenso entre os estudiosos dessa área de conhecimento sobre os princípios do DS, sendo eles: a normatividade, a equidade, a integração, e o dinamismo.

O princípio da normatividade relaciona-se com a natureza socialmente construída do DS, ou seja, expressa escolhas sociais realizadas com base nos valores que as sociedades mantêm, dependendo das visões de mundo que se quer deixar para as gerações futuras (WAAS et al., 2011). Essas escolhas remetem ao papel dos valores que devem permitir gerir a natureza de forma que as gerações futuras possam ter acesso aos recursos naturais necessários à manutenção da vida e de bem-estar social. Esses valores precisam se fundamentar em questões éticas. Essa forma de agir vai ao encontro, segundo Alencastro e Heemann (2007), Alencastro (2009), Fernandez (2011), Battestin e Ghiggi (2010), Sganzerla (2012), do que Hans Jonas denomina de Ética da Responsabilidade, na qual dadas as possíveis consequências e os riscos associados às tecnociências para transformar o mundo, hoje e no futuro, há que se refletir a respeito da responsabilidade de cada pessoa em relação a si mesma e aos outros, sejam eles humanos ou a natureza, para garantir a vida no planeta. Para os autores citados, a ética da responsabilidade enunciada por Jonas exige a avaliação das ações presentes com vistas as suas consequências atuais e futuras. Assim, embora, a solidariedade, a honestidade, a virtude, a justiça mantenham seus valores nas inter-relações diárias, é necessário acrescentar às mesmas o predomínio das ações individuais e coletivas que se refletem nas ações futuras. É neste contexto que a Carta da Terra $^{6}$ (2000) e a Declaração do Milênio ${ }^{7}$ (2000) estabelecem valores globais para a sustentabilidade. Ambos os documentos estabelecem os valores que podem balizar o cenário desejado (normativo) do

REGET - V. 20, n. 1, jan.- abr. 2016, p.306-324 
DS, dentre eles: respeito à vida, democracia, paz, liberdade, igualdade, solidariedade, proteção aos direitos humanos, não violência, tolerância, e responsabilidade comum.

Os valores são considerados, conforme Beuron et al. (2012), princípios centrais na vida das pessoas e das sociedades porque eles guiam os comportamentos/atitudes. Logo, para que haja mudança de comportamento, individual e/ou coletivo, é necessário haver alteração de valores que, por sua vez, relacionam-se com os objetivos dos indivíduos e das sociedades e com a cultura - por meio das normas (regras ou padrões) aceitas pela sociedade - gerando comportamentos considerados apropriados ou não socialmente (COSTA et al., 2004). A teoria dos valores humanos foi-se estruturando durante o século XX, no entanto, a mais recente teve o aporte teórico inicial de Shalon $\mathrm{H}$. Schwartz e Wolfgang Bilsky, em 1987, sendo depois aprimorada, em 1992, por Schwartz, que continua aprimorando-a (BEURON et al., 2012; TEIXEIRA et al., 2014). Essa teoria sugere que independente do contexto cultural, os valores possuem uma mesma estrutura axiológica, contendo cinco características principais: são crenças, são um constructo motivacional, transcendem situações específicas, guiam a seleção e avaliação de ações - políticas, pessoais e eventos - e são ordenados pela importância relativa aos demais (SCHWARTZ, 2005 apud BEURON et al., 2012). Para Schwartz, segundo Beuron et al. (2012) e Teixeira et al. (2014), o que distingue o comportamento é a motivação por meio da qual o valor foi despertado, o que implica que o contexto cultural influencia nos valores porque cada cultura pode priorizar determinado tipo motivacional em detrimento de outros. Os dez tipos motivacionais propostos por Schwartz (2005 apud BEURON et al., 2012, p. 10) são:

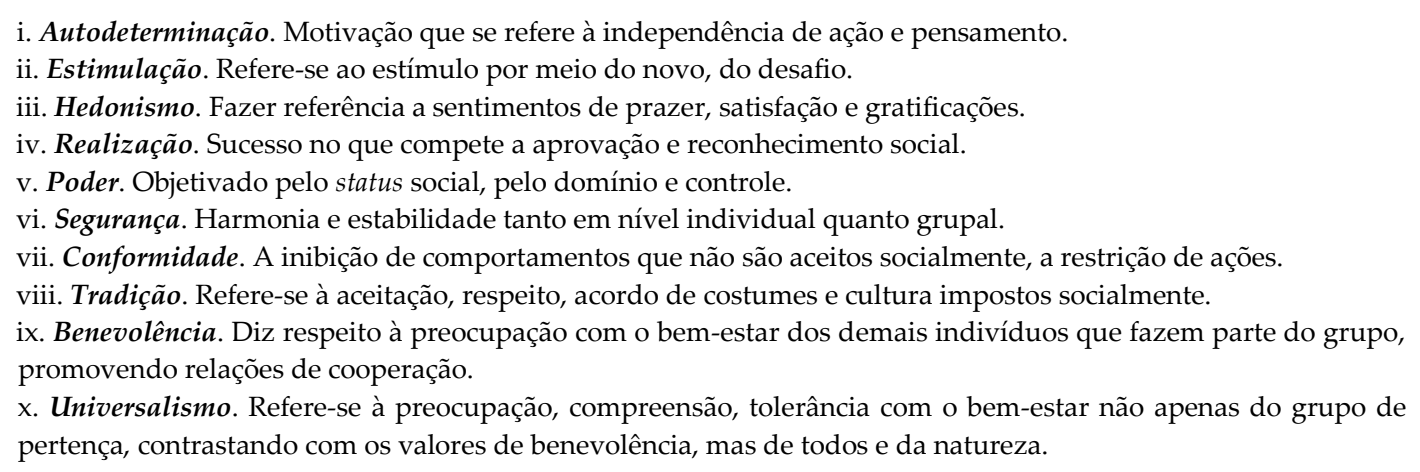

Essas motivações, por sua vez, geram três orientações: a egoística, a biosférica e a social altruística. A orientação egoística relaciona-se aos interesses individuais, a biosférica liga-se aos interesses coletivos, e a social altruística conecta-se tanto a interesses individuais quanto coletivos (BEURON et al., 2012). A relação entre as motivações e suas orientações pode relacionar-se, portanto, com comportamentos mais ou menos desejáveis do ponto de vista da sustentabilidade/DS. Assim, as motivações de orientação egoística (poder, realização, hedonismo, estimulação, autodeterminação) se relacionam negativamente com atitudes favoráveis à sustentabilidade/DS, enquanto que as de orientação biosférica (tradição, conformidade e benevolência) e social altruística (universalismo e segurança) possuem uma relação positiva (BEURON et al., 2012).

O princípio da equidade ou da justiça se divide em: intrageracional, intergeracional, geográfico, processual, e entre espécies. A equidade intrageracional se refere à igualdade social que todas as pessoas das gerações atuais deveriam ter relacionada à qualidade de vida. A equidade intergeracional, por sua vez, refere-se à manutenção da sustentabilidade no futuro (longo prazo), permitindo que as futuras gerações possam ter suas necessidades atendidas. A equidade geográfica está relacionada à necessidade de se pensar globalmente, mas agindo localmente, exigindo a cooperação em níveis local e global apontando para uma responsabilidade comum, porém, diferenciada. A equidade processual visa que os sistemas de governança ${ }^{8}$ sejam democráticos e participativos de forma que as decisões sejam tomadas envolvendo diferentes partes interessadas. A igualdade entre espécies refere-se à percepção de igualdade entre diferentes seres vivos e seus direitos à vida em igualdade com os seres humanos (WAAS et al., 2011). 
O princípio da integração pressupõe que o DS deva integrar diferentes dimensões (social, ambiental, econômica, institucional ${ }^{9}$, cultural, dentre outras) de forma a garantir que todo o sistema obtenha respostas evitando os trading-off (WAAS et al., 2011).

O princípio do dinamismo estabelece que o DS precisa ser entendido como um processo orientado para a mudança e não um estado utópico final de harmonia, pois tanto a sociedade quanto a natureza estão sujeitas a contínuas alterações. Por isso, segundo Waas et al., (2011), é necessário vislumbrar a sustentabilidade não como um destino final, mas como um destino orientado de longa viagem.

Quando se fala em sustentabilidade e DS, remete-se à necessidade de se diferenciar crescimento e desenvolvimento, tendo em vista que o crescimento econômico ilimitado não é possível. Essa impossibilidade é fruto da base material necessária para a manutenção desse crescimento, estabelecida pelos recursos naturais disponibilizados pelo planeta. Assim, crescer de forma sustentável não faz sentido, pois implica esgotamento de recursos. No entanto, o DS é possível, se o mesmo for visto numa perspectiva de mudança, evolução e progresso humano e não apenas acúmulo de bens materiais (CAVALCANTI, 2012).

Defende-se que o desenvolvimento deve ser caracterizado por mudanças qualitativas relacionadas à forma como as pessoas vivem e como as estruturas produtivas e institucionais operam (VEIGA, 2008; OLIVEIRA, 2002; CAVALCANTI, 2012). Nesse contexto, o desenvolvimento deve ser visto como "um processo complexo de mudanças e transformações de ordem econômica, política e, principalmente, humana e social" (OLIVEIRA, 2002, p. 40). Assim, o foco do desenvolvimento deve ser o desenvolvimento humano, consequentemente, a melhoria da qualidade de vida das pessoas. A melhoria da qualidade de vida é defendida por Amartya Sen (2000) para quem o desenvolvimento implica ampliação das liberdades individuais e aumento das potencialidades humanas, aumentando suas possibilidades de escolhas (ampliação das oportunidades). Para tanto, é necessário garantir-se às pessoas um mínimo de alimentação, saúde, educação, dentre outros. A satisfação das necessidades depende da organização social, do estado da tecnologia e da forma como a mesma contribui para essa emancipação, e, da participação da sociedade nos processos decisórios (PEDROSO; SILVA, 2000; VEIGA, 2008; WAAS et al., 2011). Uma vez que o desenvolvimento deve promover a liberdade requer que sejam removidas as "principais fontes de privação da liberdade: pobreza e tirania, carência de oportunidades econômicas e destruição social sistemática, negligência dos serviços públicos e intolerância ou interferência de Estados repressivos" (VEIGA, 2008, p. 34).

Nesse contexto, Cavalcanti (2012, pp. 46-47), utilizando-se das ideias de Streeten (1995), expressa que a sustentabilidade que interessa aos seres humanos baseia-se

\footnotetext{
na manutenção, reposição e crescimento dos ativos de capital, tanto físicos quanto humanos; na manutenção das condições físicas ambientais dos constituintes do bem-estar; no fortalecimento da resiliência dos sistemas terrestres, capacitando-os a ajustar-se a choques e crises; e em evitar transferir dívidas de qualquer caráter, ecológicas ou financeiras, para gerações futuras.
}

Para que se obtenha a sustentabilidade, Cavalcanti (2012) concebe que o DS deve ser visto como um processo socioeconômico no qual o uso de matéria e energia e os impactos ambientais sejam minimizados, o bem-estar social seja maximizado, e o uso dos recursos naturais vise à máxima eficiência conforme o modelo de funcionamento da natureza, ou seja, fugindo do esbanjamento.

A ONU por meio da Comissão Mundial sobre Desenvolvimento e Meio Ambiente (CMMAD) elaborou um relatório, publicado em 1987, no qual o conceito de DS mais conhecido pelo público foi estabelecido. Para a CMMAD (1991, p. 46), DS é "aquele que atende as necessidades do presente sem comprometer a possibilidade de as gerações futuras atenderem as suas próprias necessidades". Esse conceito é, segundo Waas et al. (2011), o nominal ou uma declaração de missão, podendo ser comparado a um princípio de precaução. Nesse mesmo relatório a Comissão estabelece - o que o Waas et al. (2011) denominam de conceito operacional - que o DS deva ser visto como 
um processo de transformação no qual a exploração dos recursos, a direção dos investimentos, a orientação do desenvolvimento tecnológico e a mudança institucional se harmonizam e reforçam o potencial presente e futuro, a fim de atender as necessidades e aspirações humanas (CMMAD, 1991, p. 49).

\subsection{As representações do DS}

Embora existam modelos que apresentam quatro ou mais dimensões (pilares) relacionadas ao DS, são comuns o uso de três delas: a social, a ambiental e a econômica (KEINER, 2004; WAAS et al., 2011; CAVALCANTI, 2012). Esses modelos são, comumente, representados conforme figuras 1 e 2.

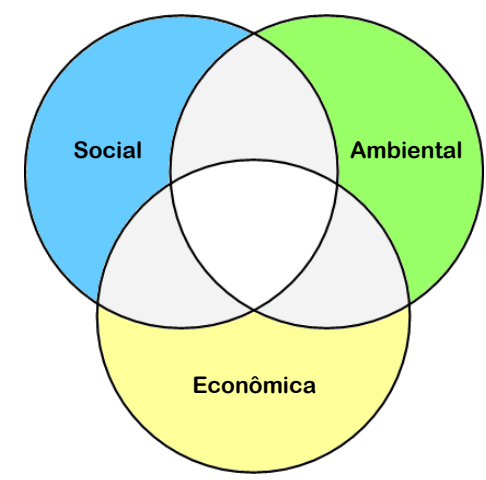

Figura 1 - As três dimensões da sustentabilidade utilizando círculos. Fonte: Adaptado de Giddings, Hopwood e O’Brien (2002).

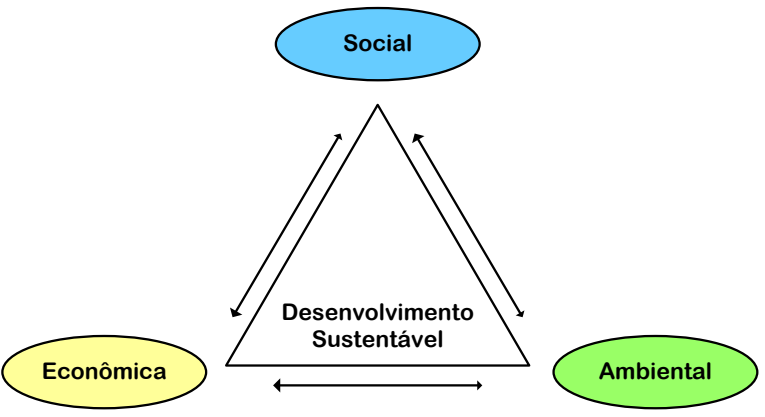

Figura 2 - As três dimensões da sustentabilidade utilizando triângulo.

Fonte: Pereira (2009).

$\mathrm{Na}$ representação do DS utilizando um triângulo (Figura 2), cada vértice representa uma dimensão (pilar) sendo o espaço interno referido ao DS. Por sua vez, na representação em que se usa a intersecção de três círculos (Figura 1), apenas a intersecção dos três aponta o DS.

Entretanto, nos últimos anos, a dimensão institucional tem sido utilizada no modelo dos pilares. Ela foi implementada pela Comissão de Desenvolvimento Sustentável das Nações Unidas (CSD - sigla em inglês) a partir da Conferência Mundial sobre Desenvolvimento Sustentável ocorrida em Johanesburgo, na África do Sul, em 2002. Essa dimensão relaciona-se com a governança e está associada à participação democrática para promover o interesse comum (WAAS et al., 2011; JACOBI, GÜNTER; GIATTI, 2012). A Figura 3 apresenta esse modelo. Nele as dimensões ambiental, econômica e institucional convergem para a dimensão social por isso a mesma se encontra no centro da figura e do processo de DS (WAAS et al., 2011). 


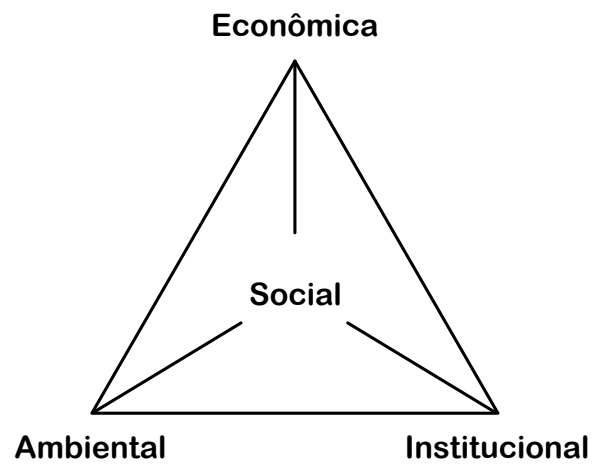

Figura 3 - As quatro dimensões da sustentabilidade.

Fonte: Waas et al. (2011).

Além dessas dimensões, há autores, dentre eles Sachs (1993) e Nascimento (2012), que defendem a necessidade de se atribuírem outras dimensões ao DS. Sachs (1993) sinaliza com as dimensões cultural e espacial, enquanto Nascimento (2012), com a política e a cultural. A Unesco (2005, p.18) vê a cultura como uma dimensão de base para o DS e que se apresenta "não apenas como manifestações específicas (música, dança, vestuário, ...), mas uma maneira de ser, de se relacionar, de se comportar, de acreditar e agir durante toda a vida, e que está em constante evolução". Esse conceito de cultura suscita a importância dessa dimensão, pois se a cultura refere-se a maneiras como as pessoas se comportam e agem, é fundamental que haja uma mudança cultural relacionada ao padrão de consumo e ao estilo de vida, por meio da alteração de valores e comportamentos, para que se possa atingir a sustentabilidade/DS. A dimensão política é importante, segundo Nascimento (2012), porque a sustentabilidade se relaciona com questões de natureza gerais, as quais ocorrem em meio a contradições e conflitos de interesse, e que, portanto, precisam de decisões e encaminhamentos coletivos.

O uso do modelo dos três pilares tem recebido críticas devido à possibilidade de as dimensões competirem entre si, exigindo que escolhas (trading-off) sejam realizadas em vez de a integração de interesses ser privilegiada. Além disso, a dimensão econômica costuma ser supervalorizada. Para suprir essas deficiências surgiu, mais recentemente, o modelo de sustentabilidade aninhado, que coloca o ambiente como limite para o desenvolvimento, pois todas as ações humanas, além de impactarem o meio ambiente, necessitam de matéria e energia que são supridas por ele (GIDDINGS; HOPWOOD; O'BRIEN, 2002; KEINER, 2004; WAAS et al., 2011). O modelo aninhado propõe colocar a sociedade dentro do ambiente conforme representado na Figura 4.

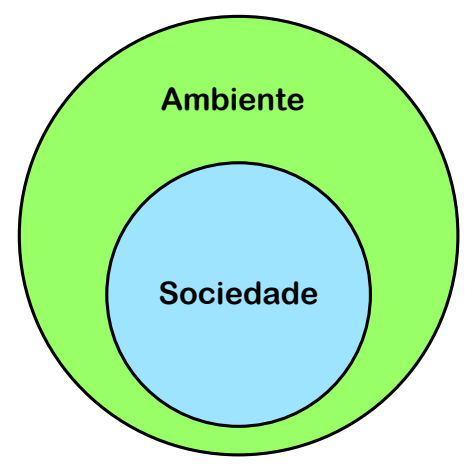

Figura 4 - A representação aninhada do DS.

Fonte: Adaptado de Giddings, Hopwood e O'Brien (2002); Waas et al. (2011).

A representação aninhada exige uma nova forma de olhar o meio ambiente e de respeito à natureza, conforme o que preconiza a Carta da Terra. Em seu preâmbulo, a Carta expõe a necessidade de união entre os povos para a promoção de uma sociedade global, na qual o respeito à natureza e aos direitos universais, a justiça econômica, e a paz devam ser cultivados, implicando que uma visão de valores básicos seja compartilhada para possibilitar a formação de um fundamento ético para a 
constituição dessa sociedade. É necessário que esses valores sejam rediscutidos e elencados, de forma a direcionar a ação das pessoas e das instituições (públicas e privadas), para subsidiar uma nova ética, na qual os vários sistemas (dimensões) da sustentabilidade sejam integrados.

Nesse contexto, a sustentabilidade, neste estudo, é concebida, conforme estabelecem Faber, Jorna e Engelen (2005) e Osório, Lobato e Castilho (2005), como a capacidade de manutenção de um estado visando à conservação da vida. Enquanto, o entendimento de DS deve ser de um processo de desenvolvimento em constante adaptação da sociedade na busca por qualidade de vida, incluindo a satisfação de suas necessidades básicas e de ampliação de suas liberdades e potencialidades. Nesse processo, as várias dimensões do DS estão imbricadas e são interdependentes. Assim, o DS aponta para uma dinâmica de transição necessária para que as gerações futuras possam ter as mesmas chances que as gerações atuais de desfrutarem uma vida saudável e digna. Para tanto, mudanças estruturais, nas diversas dimensões do DS, são necessárias. Entretanto, elas devem ocorrer por meio de um equilíbrio dinâmico entre essas dimensões, para que se possam gerir sociedades sustentáveis (PEDROSO; SILVA, 2000; WAAS et al., 2011; CAVALCANTI, 2012). Pelo exposto percebe-se que o ser humano é o centro do processo de construção do DS, conforme representado na Figura 5.

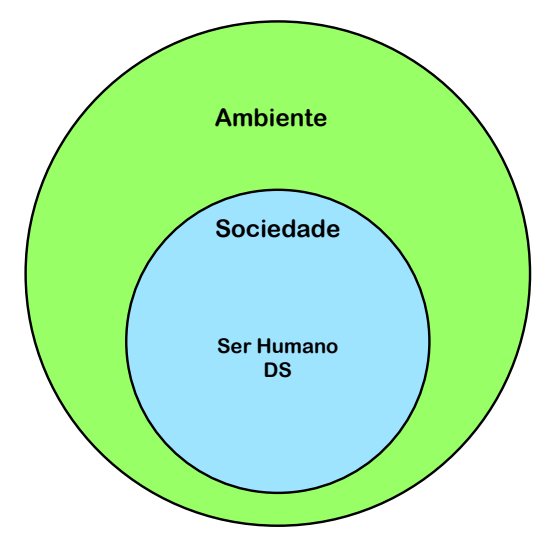

Figura 5 - Representação do DS com foco no ser humano.

Fonte: Adaptado de Giddings, Hopwood e O’Brien (2002); Waas et al. (2011) e Pervanchon (2007 apud Vilela e Costa, 2010).

\subsection{Sustentabilidade e cidadania}

Educar para a cidadania implica, segundo Quevedo (2011) e Jacobi (2005), possibilitar processos educacionais que capacitem as pessoas a exercerem seus direitos de escolhas e que lhes assegurem a sua dignidade social. Dessa forma, para Jacobi (2005) e Unesco (2005), a EDS/EpS pressupõe uma formação com foco na cidadania participativa, na qual as pessoas devem ser formadas para discutirem e refletirem sobre os problemas coletivos e participarem de decisões acerca do destino das sociedades. A cidadania participativa poderá fortalecer o princípio da normatividade, que segundo Waas et al. (2011), relaciona-se com a natureza socialmente construída do DS, e que se expressa por meio das escolhas sociais que devem ser realizadas com base em valores sociais relativos às gerações futuras.

Como o conceito de DS pressupõe o atendimento das necessidades não apenas atuais, mas, também, das futuras gerações, isso implica lidar com múltiplas e complexas dimensões, portanto, fazse necessário o aprofundamento e a reflexão das questões éticas. A ética necessária à sustentabilidade/DS deve possuir o cerne da responsabilidade, conforme delineada pelo filósofo alemão Hans Jonas. Essa filosofia trabalha com a ideia de que, dados os riscos que incidem sobre a sociedade atual devido às tecnociências, cada pessoa é responsável por si mesma e pelos outros (pessoas e outros seres) nas ações presentes e futuras (ALENCASTRO; HEEMANN, 2007; ALENCASTRO, 2009; FERNANDEZ, 2011; BATTESTIN; GHIGGI, 2010; SGANZERLA, 2012). Para Buarque (1994) é preciso que as sociedades mudem seu foco de modernidade, atualmente centrada na técnica, para uma centralização na ética, pois se a técnica faz dos meios um fim em si, a ética que deve reger a sustentabilidade, reposiciona os fins como referência primordial num cenário de complexas e múltiplas dimensões econômica, política, ambiental, social, cultural, dentre outras. Assim, o desafio a 
ser enfrentado pela EDS/EpS é o de "deslocar o eixo da lógica dos meios a serviço da acumulação, num curto espaço de tempo, para uma lógica dos fins em função do bem-estar social, do exercício da liberdade e da cooperação entre os povos" (FURTADO, 1992 apud GONÇALVES, 2005).

Dessa forma, as mudanças necessárias à sustentabilidade/DS poderão ocorrer se valores éticos forem compartilhados. Há, nesse ponto, um forte atrelamento do DS com educação, pois por meio dela novos valores podem ser apreendidos e utilizados. Além desse aspecto, Vega et al. (2009), sugerem que há uma relação biunívoca entre educação e desenvolvimento, pois para eles, ainda que se reconheça a educação como um direito fundamental das pessoas, são os sistemas educativos dominantes que determinam o tipo de pessoas (valores) e de sociedades que prevalecem e consequentemente, o grau, a forma e, sobretudo, o tipo de desenvolvimento que se vislumbra obter. Os autores sugerem que as ações e os métodos que se utilizam para obtenção do tipo de desenvolvimento almejado são determinados pelas estruturas ideológicas que suportam os sistemas educativos. Por isso, eles apontam que a EDS/EpS pode obter êxito na obtenção de sociedades mais justas e sustentáveis. Para tanto, essa educação deve qualificar as pessoas a perceberem o mundo formado por vários subsistemas, relacionados e interdependentes, dos quais elas dependem para continuarem a existir (CAVALCANTI, 2012; VEGA et al., 2009; FOLHEDO, 2000; PEDROSO; SILVA, 2000).

\section{Considerações Finais}

Este artigo enfatizou como a educação - diante da crise socioambiental que as sociedades enfrentam e perante os desafios que a mesma suscita - embora não possa sozinha reverter o quadro atual de insustentabilidade, tem muito a contribuir para tornar as sociedades sustentáveis. Para tanto, é preciso formar pessoas capazes de refletirem sobre a forma como essas sociedades estão estruturadas, e a partir dessa reflexão buscar soluções democráticas para construírem um mundo melhor, no qual possam coexistir a justiça social e a equidade. Em nível internacional, é por meio da implementação da sustentabilidade/DS nos currículos dos vários níveis de ensino que se tem procurado viabilizar as mudanças necessárias.

Acredita-se que a implementação da sustentabilidade/DS no ensino superior permitiria um avanço significativo de melhoria socioambiental uma vez que os técnicos em nível superior atuam em muitas atividades impactantes e, consequentemente, refletirem sobre sua atuação poderia fazer-lhes atuar com maior responsabilidade. Em relação à engenharia, esses impactos, muitas vezes, são prejudiciais à qualidade de vida das pessoas, de outros seres vivos e dos ecossistemas, logo, é imprescindível que os futuros engenheiros(as) possam refletir sobre sua atuação e sejam formados para buscarem soluções sustentáveis para os problemas profissionais que encontrarão, colaborando, assim, com a sociedade na qual atuam. Isso exige uma formação generalista, humanista, crítica e reflexiva que permita aos engenheiros(as) identificarem e resolverem problemas considerando seus aspectos políticos, sociais, ambientais, técnicos, econômicos, culturais, dentre outros.

Além disso, para auxiliar a minimizar o enfoque ambiental e fortalecer a existência de várias dimensões atreladas à sustentabilidade/DS, sugere-se trabalhar na formação em engenharia conforme propõem Faber, Jorna e Engelen (2005), vendo os sistemas artificiais (construções humanas) como artefatos, que, normalmente, quando afetados por desequilíbrios, não conseguem restabelecer suas capacidades, podendo chegar ao colapso. Como os sistemas artificiais dependem dos sistemas naturais para subsistirem e também para serem "degradados" não se pode descuidar de se identificarem previamente os impactos que os sistemas artificiais podem produzir no contexto socioambiental. Assim, entende-se ser importante verificar para os sistemas artificiais, foco de estudo das diferentes áreas de engenharia, a maneira de avaliar a sua sustentabilidade por meio dos três aspectos propostos por Faber, Jorna e Engelen (2005) - o tipo de artefato (entidade ou construto); a orientação a objetivos (absoluta ou relativa); e, a interação comportamental (estática ou dinâmica) permitindo aos(as) engenheiros(as) visualizarem os problemas em sua totalidade e proporem soluções técnicas que possam minimizar seus impactos negativos e maximizar os positivos em suas múltiplas dimensões. 


\section{Notas}

1 Entende-se visão de mundo como um conjunto de características culturais partilhadas por segmentos da sociedade condicionadas ideologicamente. Essas características traduzem-se em crenças e valores partilhados por grupos sociais (CESAR; CIDADE, 2003; HESS; STROBEL, 2013). É, na concepção de Torres (2005), uma janela conceitual por meio da qual as pessoas percebem e interpretam o mundo, tanto para compreendê-lo quanto para transformá-lo, se possível.

2 Sociedades sustentáveis são aquelas ancoradas em uma visão transformadora da realidade, na qual há diversidade de buscas e soluções para a construção simultânea e coletiva da sustentabilidade social, ambiental, econômica, política e ética (HENRIQUES et al., 2007).

3 A noção de competência neste trabalho é a representada pela interação dinâmica entre as dimensões conhecimentos, habilidades e atitudes, que estão latentes na pessoa, transformando-se em competência quando colocadas em ação num dado contexto, definido por Cheethan e Chivers (1996) como uma situação em que a pessoa precisa atuar. Entretanto, para que a competência exigida pelo contexto seja colocada em ação, à pessoa precisa mobilizar recursos (físicos, culturais, sociais, dentre outros) do ambiente. As dimensões conhecimentos, habilidades e atitudes não podem ser vistas como dimensões isoladas, pelo contrário, precisam ser entendidas, conforme Perkins e Solomon (1989 apud Allal, 2004, p. 83), como "uma rede integrada e funcional constituída por componentes cognitivos, afetivos, sociais, sensório-motores, capaz de ser mobilizada em ações finalizadas diante de uma família de situações".

4 As competências para a sustentabilidade são "um conjunto complexo e integrado de conhecimentos, destrezas, habilidades, atitudes e valores que as pessoas utilizam em distintos contextos (sociais, educativos, laborais, familiares) para resolver situações relacionadas com a problemática do desenvolvimento, assim como para operar e transformar a realidade com critérios de sustentabilidade" (GELI apud AZNAR MINGUET e ULL SOLÍS, 2009, p. 229 - tradução nossa).

5 Acreditação é um processo mediante o qual uma agência ou associação legalmente responsável concede reconhecimento público a uma escola, instituto, colégio, universidade ou programas de ensino que alcançam certos padrões e qualidades educacionais previamente estabelecidos. [...] O propósito do processo de acreditação é proporcionar uma avaliação profissional aceitável e de qualidade para as instituições educativas e os programas educacionais com intuito de estimular a melhoria constante dos mesmos (THE INTERNATIONAL ENCYCLOPEDIA OF HIGHER EDUCATION, 1997 apud MARQUES e MARQUINA, 1998, p. 67 - tradução nossa).

6 A Carta da Terra é resultado de mais de uma década de reflexões da sociedade civil sobre objetivos comuns e valores compartilhados, visando uma interpretação integradora do DS. Em 2000 a Comissão da Carta da Terra, uma entidade internacional independente, concluiu e divulgou esse documento (UNESCO, 2005).

7 A Declaração do Milênio é um documento elaborado pela ONU, na Conferência de Nova Iorque, em setembro de 2000. Ela reflete as preocupações de 191 países e da ONU sobre os problemas relacionados com a pobreza extrema, a falta de água potável e de educação para todos, e, a possibilidade de se alcançar outros objetivos no domínio do desenvolvimento (NAÇÕES UNIDAS, 2000).

8 A governança representa um enfoque conceitual que aponta para uma mudança na forma de governar, no qual o foco é a participação. São caminhos teóricos e práticos de interação entre o governo e os atores sociais públicos e privados, incluindo leis, regulação e instituições, políticas e ações de governo, iniciativas locais, redes de influência, mercados, dentre outros que sofrem a 
influência dos sistemas políticos nos quais estão inseridos. Essa participação implica mais democracia, porém, exige mais responsabilidade de todos (WAAS et al., 2011; JACOBI; GÜNTER; GIATTI, 2012).

9 A dimensão institucional de qualquer processo corresponde ao conjunto de todas as regras formais e informais que moldam a natureza de sua identidade, influenciam a intensidade e qualidade de sua dinâmica e direcionam os compromissos associados a seu propósito. Entre essas "regras do jogo" encontram-se as leis, políticas, premissas, enfoques, planos, prioridades, estratégias, normas, mecanismos institucionais, etc. (SILVA, 2001, p. 17-18). Compõem essa dimensão, segundo Krama (2008), as formas de governo, legislações, organizações e sociedade civil, que formam a base operacional sobre a qual o DS pode se estabelecer. Atualmente, vários indicadores de sustentabilidade consideram essa quarta dimensão juntamente com o tripé convencional (social, ambiental e econômico) para o estabelecimento de indicadores de DS (BELLEN, 2004; SANTOS, 2009; MELO; SALLES; BELLEN, 2012).

\section{Referências}

ADEODATO, M. T. P. C.; SILVA, M. R.; SHIMBO, I. TEIXEIRA, B. A. N. O ensino da sustentabilidade em cursos de graduação em engenharia civil integrando pesquisa e extensão: a experiência da UFSCar. In: CONGRESSO BRASILEIRO DE EDUCAÇÃO EM ENGENHARIA, setembro de 2004, Brasília. Disponível em http://www.abenge.org.br/cobenges-anteriores/2004/artigos-2004/artigos-publicados 6 . Acesso em 20 março de 2013.

ADLONG, W. Rethinking the Talloires Declaration. International Journal of Sustainability in Higher Education, v. 14, n. 1, p. 56-70, 2013.

ALENCASTRO, M. S. C. Hans Jonas e a proposta de uma ética para a civilização tecnológica. Desenvolvimento e Meio Ambiente, n. 19, p. 13-27, jan./jun. 2009.

ALLAL, L. Aquisição e avaliação das competências em situação escolar. In: DOLZ, J.; OLLAGNIER, E (Orgs). O enigma da competência em educação. Porto Alegre: Artmed, p. 79-96, 2004.

ALENCASTRO, M. S. C.; HEEMANN, A. A responsabilidade como substrato ético da sustentabilidade: considerações a partir da obra de Hans Jonas. In: II SEMINÁRIO SOBRE SUSTENTABILIDADE, 2007, Curitiba. Disponível em http://sottili.xpg.uol.com.br/publicacoes/pdf/Isseminario/pdf reflexoes/reflexoes 18.pdf. Acesso em $12 / 06 / 2012$.

AZNAR MINGUET, P., ULL SOLÍS, M. A. La formación de competencias básicas para el desarrollo sostenible: el papel de la Universidad. Revista de Educación, n. extraordinario, p. 219-237, 2009.

BARBIERI, J. C.; SILVA, D. da. Desenvolvimento sustentável e educação ambiental: uma trajetória comum com muitos desafios. RAM, Rev. Adm. Mackenzie, v. 12, n. 3, edição especial, São Paulo, SP, p. 51-82, maio/jun. 2011.

BARTH, M.; GODEMANN, J.; RIECKMANN, M.; STOLTENBERG, U. Developing key competencies for sustainable development in higher education. International Journal of Sustainability in Higher Education, v. 8, n. 4, p. 416-430, 2007.

BATTESTIN, C.; GHIGGI, G. O princípio responsabilidade de Hans Jonas: um princípio ético para os novos tempos. Thaumazein, Ano III, n. 6, p. 69-85, out/2010. 
BAZZO, W. A.; PEREIRA, L. T. do V.; LINSINGEN, I. Von. Educação tecnológica: enfoques para o ensino de engenharia. Florianópolis: Editora da UFSC, 2000.

BELLEN, H. M. V. Desenvolvimento Sustentável: uma descrição das principais ferramentas de avaliação. Ambiente \& Sociedade, v. VII, n. 1, p. 67-87, jan./jun. 2004.

BEURON, T. A.; SCHUCH JÚNIOR, V. F.; MADRUGA, L. R. R. G.; CARPES, A. M.. Relações entre os valores pessoais e os comportamentos ecológicos no contexto da sustentabilidade. Revista Ibero Americana de Ciências Ambientais, Aquidabã, v.3, n.2, p. 6-22, 2012.

BRASIL. Conselho Nacional de Educação. Câmara de Educação Superior. Resolução 11/2002, aprovada em 11 de março de 2002. Institui diretrizes curriculares nacionais para os cursos de graduação em engenharia.

BRITO, W. A. de. Proposta de construção de um currículo integrado de engenharia. In: XXXIX CONGRESSO BRASILEIRO DE EDUCAÇÃO EM ENGENHARIA. Blumenau/SC, 03 a 06 de outubro de 2011. Disponível em http://www.abenge.org.br/CobengeAnteriores/2011/sessoestec/art2114.pdf. Acesso em 05/05/2012.

BUARQUE, C. A revolução nas prioridades: da modernidade técnica à modernidade ética. São Paulo: Paz e Terra, 1994.

CARLETTO, M. R. Avaliação de Impacto tecnológico: reflexões, fundamentos e práticas. 1.ed. Curitiba: Ed. UTFPR, 2011.

CARVALHO, A. C. B. D. de.; PORTO, A. J. V.; BELHOT, R. V. Aprendizagem significativa no ensino de engenharia. Revista Produção, v. 11, n. 1, p. 81-90, nov/2001.

CAVALCANTI, C. Sustentabilidade: mantra ou escolha moral? Uma abordagem ecológico-econômica. Estudos Avançados, v. 26, n. 74, p. 35-50, 2012.

CESAR, L. P. de M.; CIDADE, L. C. F. Ideologia, visões de mundo e práticas socioambientais no paisagismo. Sociedade e Estado, Brasília, v. 18, n. 1-2, p. 115-136, 2003.

CHEETHAM, G.; CHIVERS, G. Towards a holistic model of professional competence. Journal of European Industrial Training, v. 20, n. 5, p. 20-30, 1996.

CMMAD (Comissão Mundial para o Meio Ambiente e Desenvolvimento). Nosso Futuro Comum. 2 ed. Rio de Janeiro: Ed. Da Fundação Getúlio Vargas, 1991. 430 p.

CORDEIRO, J. S.; ALMEIDA, N. N.; BORGES, M. N.; DUTRA, S. C.; VALINOTE, O. L.; PRAVIA, Z. M. C. Um futuro para a educação em engenharia no Brasil: desafios e oportunidades. Revista de Ensino de Engenharia, v. 27, n. 3, Edição especial, p. 69-82, 2008.

CORTESE, A. D.; HATTAN, A. S. Education for sustainability as the mission of higher education. Sustainability, v. 3, n.1, p. 48-52, fev/2010.

COSTA, A. F. M.; STUTZ, B. L.; MOREIRA, G. de O.; GAMA, M. M. da. Sociedade atual, comportamento humano e sustentabilidade. Caminhos de Geografia, v. 5, n. 13, p. 209-220, Out/2004.

DOBSON, A.; QUILLEY, S.; YOUNG, W. Sustainability as competitive advantage in higher education in the UK. International Journal of Environment and Sustainable Development, v. 9, n. 4, p. 330-348, 2010. 
DWEK, M.; COUTINHO, H.; MATHEUS, F. Por uma formação crítica em engenharia. In: XXXIX CONGRESSO BRASILEIRO DE EDUCAÇÂO EM ENGENHARIA. Blumenau/SC, 03 a 06 de outubro de 2011. Disponível em http://www.abenge.org.br/CobengeAnteriores/2011/sessoestec/art2114.pdf. Acesso em 05/05/2012.

EDWARDS, M.; ÁLVAREZ-SÁNCHEZ, D.; SÁNCHEZ-RUIZ, L. M. Engineering education and competences for sustainability education in Spain. In: INTERNATIONAL CONFERENCE ON ENGINEERING EDUCATION - ICEE, Coimbra/Portugal, 3 a 7 de setembro de 2007. Disponível em http://digital.csic.es/bitstream/10261/10157/1/AC215 1 ICEEMonica.pdf. Acesso em 03/05/2010.

FABER, N. JORNA, R. ENGELEN, J. V. The sustainability of "sustainability" a study into the conceptual foundations of the notion of "sustainability". Journal of Environmental Assessment Policy and Management, v. 7, n. 1, p. 1-33, 2005.

FERNANDEZ, B. P. M. Ecodesenvolvimento, desenvolvimento sustentável e economia ecológica: em que sentido representam alternativas ao paradigma de desenvolvimento tradicional? Desenvolvimento e meio ambiente, n. 23, p.109-120, jan/jun 2011.

FOLHEDO, M. Raciocínio sistêmico: uma boa forma de se pensar o meio ambiente. Ambiente \& Sociedade, Ano III, n. 6/7, p. 105-144, 2000.

GIDDINGS, B; HOPWOOD, B.; O'BRIEN, G. Environment, economy and society: fitting them together into sustainable development. Sustainable Development, n. 10, p. 187-196, 2002.

GONÇALVES, D. B. Desenvolvimento sustentável: o desafio da presente geração. Revista Espaço Acadêmico, n. 51, ago/2005.

HANNING, A.; ABELSSON, A. P.; LUNDQVIST, U.; SVANSTRÖM, M. Are we educating engineers for sustainability?: Comparison between obtained competences and Swedish industry's needs. International Journal of Sustainability in Higher Education, v. 13, n. 3, p. 305-320, 2012.

HENRIQUES, R.; TRAJBER, R.; MELLO, S.; LIPAI, E. M.; CHAMUSCA, A. Educação Ambiental: aprendizes de sustentabilidade. Brasília: SECAD/MEC, 2007. 109p. Disponível em http://portal.mec.gov.br/dmdocuments/publicacao2.pdf. Acesso em 30/05/2011.

HESS, J. L.; STROBEL, J. Sustainability and the engineering worldview. In: FRONTIERS IN EDUCATION CONFERENCE, 2013, IEEE. 23 a 26 Oct. 2013, Oklahoma City, p. 644-648. Disponível em

file:///C:/Documents\%20and\%20Settings/Valentim/Meus\%20documentos/Downloads/Hess Strobel 20 13 FIE.pdf. Acesso em 15/11/2014.

JACOBI, P. R. Educação ambiental: o desafio da construção de um pensamento crítico, complexo e reflexivo. Educação e Pesquisa, São Paulo, v. 31, n. 2, p. 233-250, Maio/Agosto/2005.

JACOBI, P. R; RAUFFLET, E.; ARRUDA, M. P. De. Educação para a sustentabilidade: reflexão sobre paradigmas e práticas. RAM, Rev. De Adm. Mackenzie, v. 12, n. 3, edição especial, p. 21-50, 2011.

JACOBI, P. R.; GÜNTHER, W. M. R.; GIATTI, L. L. Agenda 21 e governança. Estudos Avançados, v. 26, n. 74, p. 331-339, 2012.

JICKLING, B.; WALS, A. E. J. Globalization and environmental education: looking beyond sustainable development. Journal Curriculum Studies, v. 40, n. 1, p. 1-21, 2008. 
KEINER, M. Re-emphasizing sustainable development - the concept of 'evolutionability': on living chances, equity, and good heritage. Environment, Development and Sustainability, 6, p. 379-392, 2004.

KRAMA, M. R. Análise dos indicadores de desenvolvimento sustentável no Brasil, usando a ferramenta painel de sustentabilidade. Dissertação (Mestrado em Engenharia de Produção). 171p. Pontifícia Universidade Católica do Paraná. Curitiba, 2008.

LAYRARGUES, P. P. Gestão ambiental e universidades: um caminho pedagógico para a

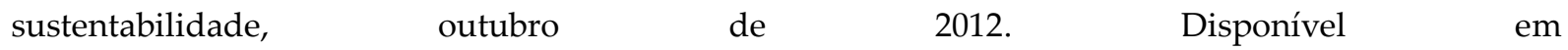
http://www.foruns.unicamp.br/foruns/projetocotuca/biblioteca virtual/arquivos/Phillpi.pdf. Acesso em 01/06/2013.

LIMA, G. da C. O discurso da sustentabilidade e suas implicações para a educação. Ambiente e Sociedade, v.6, n.2, p. 99-119, 2003.

LINSINGEN, I. V. Engenharia, tecnologia e sociedade: novas perspectivas para uma formação. 2002. Tese (Doutorado em Educação). 221 p. Universidade Federal de Santa Catarina, Florianópolis, 2002.

LINSINGEN, I. V. O enfoque CTS e a educação tecnológica: origens, razões e convergências curriculares. Disponível em file://C:/Documents\%20and\%20Settings/Valentim/Meus\%20documentos/Downloads/551bd09a0cf2fe6 cbf75ed53\%20(1).pdf. Acesso em 20/07/2012.

LINSINGEN, I. V.; PEREIRA, L. T. do V.; BAZZO, W. A. O enfoque CTS e a formação em engenharia: convergências curriculares. In: CONGRESSO BRASILEIRO DE ENSINO EM ENGENHARIA. Rio de janeiro, set/ 2003. Disponível em http://www.abenge.org.br/CobengeAnteriores/2003/artigos/OUT660.pdf. Acesso em 02/08/2011.

MANTEAW, B. O. Education in global environmental politics: why the discourse of education for sustainable development needs attention. International Journal Environment and Sustainable development, v. 9, n. 1/2/3, p. 74-90, 2010.

MARQUES A.; MARQUINA, M. Evaluación, acreditación, reconocimiento de títulos y habilitación. Enfoque comparado. Serie informes. Buenos Aires: Coneau, 1998. Disponível em http://www.coneau.edu.ar/archivos/1328.pdf. Acesso em 04/09/2014.

MARTíneZ AGUT, M. P.; MINGUeT, P. A.; UlL SOlíS, A.; PIÑERO, A. Promoción de la sustentabilid en los currícula de la enseñanza superior desde el punto de vista del profesorado: un modelo de formación por competencias. Educatio Siglo XXI, n. 25, p. 187-208, 2007.

MELO, P. T. N. B.; SALLES, H. K.; BELLEN, H. M. V. Quadro institucional para o desenvolvimento sustentável: o papel dos países em desenvolvimento com base na análise crítica do discurso da Rio+20. Cad. EBAPE.BR, v. 10, n. 3, p. 701-720, opinião 1, Rio de Janeiro, Set/2012.

MINTZ, K.; TAL, T. Education for sustainability in higher education: a multiple-case study of three courses. Journal of Biological Education, v. 47, n. 3, p.140-149, 2013.

MORAES, N. Educação ambiental nos cursos de engenharia da Universidade Tecnológica Federal do Paraná câmpus Curitiba. 2011. Tese (Doutorado em Educação). 220 p. Universidad Del Mar. Viña del Mar, Chile, 2011. 
MULDER, K. F.; SEGALÀS, J.; FERRER-BALAS, D. Educating engineers for/in sustainable development? what we knew, what we learned, and what we should learn. Thermal science, v. 14, n. 3, p. 625-639, 2010.

NAÇÕES UNIDAS. Declaração do Milénio. Cimeira do Milénio, Nova Iorque, 6-8 de Setembro de 2000. Disponível em http://www.pnud.org.br/Docs/declaracao do milenio.pdf. Acesso em 10/05/2014.

NASCIMENTO, E. P. do. Trajetória da sustentabilidade: do ambiental ao social, do social ao econômico. Estudos avançados, v. 26, n. 74, p. 51-64, 2012.

OLIVEIRA, G. B. de. Uma discussão sobre o conceito de desenvolvimento. Revista da FAE, Curitiba, v.5, n.2, p. 37-48, maio/ago 2002..

OSORIO, L. A. R.; LOBATO, M. O.; CASTILLO, X. A. Del. Debates on sustainable development: towards a holistic view of reality. Environment, Development and Sustainability, 7, p. 501-518, 2005.

PEDROSO, E. A.; SILVA, T. N. da. O desenvolvimento sustentável e a abordagem sistêmica. READ, ed. 18 , v. 6, n. 6, p. 1-36, nov/dez 2000.

PEREIRA, J. V. I. Sustentabilidade: diferentes perspectivas, um objetivo comum. Economia Global e Gestão, v. 14, n. 1, p. 115-126, Lisboa, abril/2009.

QUELHAS, O. L. G.; FRANÇA, S. L. B.; TRAVINCAS, R. O ensino da sustentabilidade na formação do engenheiro: proposta de diretrizes. In: VII CONGRESSO NACIONAL DE EXCELÊNCIA EM GESTÃO. Agosto de 2011. Rio de Janeiro, Brasil. Disponível em http://www.excelenciaemgestao.org/portals/2/documents/cneg7/anais/t11 0414 1948.pdf. Acesso em 04/03/2012.

QUEVEDO, M. de. Educação professional no Brasil: formação de cidadãos ou mão de obra para o mercado de trabalho? Revista humanidades, tecnologia e cultura, v. 1, n. 1, p. 147-159, 2011.

RATTNER, H. Meio ambiente e desenvolvimento sustentável: o mundo na encruzilhada da História. Revista Espaço Acadêmico, Ano II, n. 14, julho de 2002.

RIECKMANN, M. Future-oriented higher education: which key competencies should be fostered through university teaching and learning? Futures, v. 44, n. 2, p. 127-135 Special Issue: University Learning, mar/2012.

ROHWEDER, L.; VIRTANEN, A. Developing the model on the learning for sustainable development in higher education. Journal of Teacher Education for Sustainability, v. 11, n. 1, p. 31-42, 2009.

SACHS, I. Estratégias de transição para o século XXI: desenvolvimento e meio ambiente. São Paulo: Studio Nobel/Fundap, 1993.

SANTOS, M. F. R. F. Sistemas de indicadores de desenvolvimento sustentável: um estudo do modelo suíço. GEPROS. Gestão da Produção, Operações e Sistemas, Ano 4, n. 3, p. 11-23, Jul-Set/2009.

SANTOS, R.; ANDRIOLI, A. I. Educação, globalização e neoliberalismo: o debate precisa continuar! Revista Iberoamericana de Educación (Online), Espanha, v. 35, n.1, p. 1-14, 2005.

SEGALÀS, J. Educating Engineers for Sustainability. Why? What? How? Sostenible?, n. 10, p. 117-132, 2008.

SEN, A. Desenvolvimento como liberdade. São Paulo: Companhia das Letras, 2000. 
SGANZERLA, A. Natureza e responsabilidade: Hans Jonas e a biologização do ser moral. 2012. Tese. (Doutorado em Filosofia). 270p. Universidade Federal de São Carlos. São Carlos/SP, 2012.

SILVA, J de S. La dimensión institucional del desarrollo sostenible. Pontificia Universidad Católica del Ecuador sede Ibarra (PUCE-I), 2001.

TEIXEIRA, M. L. M.; SAMBIASE, M. F.; JANIK, M.; BILSKY, W. Peculiaridades da estrutura de valores básicos dos brasileiros. Revista Psicologia: Organizações e Trabalho, v. 14, n. 2, p. 139-152, abr/jun 2014.

TONINI, A. M.; DUTRA, L. F. Formação tecnológica: responsabilidade e desenvolvimento social. Em Extensão, Uberlândia, v. 8, n. 2, p. 33-38, 2009.

TORRES, J. J. M. Teoria da complexidade: uma nova visão de mundo para a estratégia. In: I ENCONTRO BRASILEIRO DE ESTUDOS DA COMPLEXIDADE - I EBEC. Curitiba, 11 a 13 de julho/2005. Disponível em http://wp.ufpel.edu.br/consagro/files/2010/09/TORRES-Teoria-DaComplexidade-e-Estrategia.pdf. Acesso em 10/07/2011.

TOZZONI-REIS, M. F. de C. Educação e sustentabilidade: relações possíveis. Olhar de Professor, 14 (2), p. 293-308, 2011.

ULL SOlÍS, M. A.; MARTÍNEZ AGUT, M. P.; PIÑERO, A; AZNAR MINGUET, P. Análisis de la introducción de la sostenibilidad en la enseñanza superior en europa: compromisos institucionales y propuestas curriculares. Rev. Eureka Enseñ. Divul. Cien., 7, n. Extraordinario, p. 413-432, 2010.

UNESCO. Década das Nações Unidas para um Desenvolvimento Sustentável, 2005-2014: documento final do esquema internacional de implementação. Brasília: UNESCO, 2005.

VEGA, P.; FREITAS, M.; ÁLVAREZ, P.; FLEURI, R. Educación Ambiental e Intercultural para la sostenibilidad: fundamentos y praxis. Utopía y Praxis Latinoamericana, ano 14, n. 44, p. 25-38, 2009.

VEIGA, J. E. da. Desenvolvimento Sustentável: o desafio do século XXI. 3.ed. Rio de Janeiro: Garamond, 2008.

VILELA, A. A.; COSTA, M. R. Agricultura sustentável: conceitos. Rev. de Ciências Agrárias [online], v, 33, n.2, p. 61-74, 2010.

WAAS, T.; HUGÉ, J.; VERBRUGGEN, A.; WRIGHT, T. Sustainable Development: A Bird's Eye View. Sustainability, 3, p. 1637-1661, 2011.

WRIGHT, T. S. S. Definitions and frameworks for environmental sustainability in higher education. International Journal of Sustainability in Higher Education, v. 3, n. 3, p. 203-220, 2002.

WRIGHT, T. S. S. Sustainability, internationalization, and higher education. New Directions for Teaching and Learning, n. 118, p. 105-115, Summer/2009. 